showing that, given certain sufficient predisposing causes on the part of certain individuals, a virulent strain of bacillus coli introduced into the alimentary canal, especially after some cultivation in the domestic milk-supply, may cause an extensive epidemic affecting seriously the health of a district.

- in the

I am much indebted to Professor J. Glaister for his kindness in allowing me to carry out the investigations in the University of Glasgow Pablic Health laboratory.

Hamilton, N.B.

\section{A READY METHOD OF DIFFERENTIATING STREPTOCOCCI AND SOME RESULTS ALREADY OBTAINED BY ITS APPLICATION.}

BY M. H. GORDON, M.A., M.D., B.Sc. OxoN. (From the Research Laboratory, St. Bartholomen's Hospital, E.C.)

Although few bacteria have been more debated in the past than streptococci, the fundamental question whether all streptococci are varieties of one, or whether different species exist, is a matter upon which the majority of bacteriologists do not appear set to have come to a definite conclusion, and for the reason that absolutely convincing evidence upon which to decide that issue has hitherto been lacking. This uncertainty with regard to the relationship of streptococci to one another is in marked contrast to the pathogenic importance of the group. Apart from cases of erysipelas and sepsis-puerperal or other-it is well known that in the complications and fatal issue of a large number of acute and chronic diseases streptococci play an exceedingly important etiological part. Exactly how important that part is will not be adequately understood until bacteriological examination becomes more a feature of clinical practice than it is at the present time. The fortuitous element that now attends the employment of antistreptococcic sera, even in cases where streptococci have been definitely ascertained to be at work, is certainly not in favour of the unity of streptococci. It is a necessary outcome, however, of ignorance as to the diversity that obtains amongst them.

The characters of streptococci that have been most studied hitherto' ${ }^{2}$ have been their morphology (both macroscopic and microscopic); their growth upon gelatin, agar, potato, and in litmus milk; their virulence for mice and rabbits: and more recently their agglutinative and hæmolytic properties. Marmorek also introduced a test which consists of examining the capacity of a streptococcus of growing in the filtrate of a fluid in which another streptococcus has previously been cultivated. As already mentioned, however, the evidence obtained by comparing streptococci in respect of these points has not been of so convincing a nature as to cause the majority of bacteriologists to abandon their position of reserve, and the question naturally arises-Are these properties of streptococci that have been so exclusively studied hitherto, and with such unconvincing result, the best properties by which cocci of this class may be differentiated?

In the following paper I shall bring forward evidence to show that, over and above the characters in question, there are other inherent qualities of streptococci, qualities by means of which distinct types of streptococci may se dily be discerned and identified. The differential characters referred to were discovered and applied in course of an investigation which I have had the honour to carry out during the past few years on behalf of the Local Government Board and, as full details of the various stages and results of that inquiry are contained in the reports of the medical officer for 1902-03 and 1903-04 respectively, I shall here only refer to the chief results that have been obtained up to the present time by an examination of the streptococcus group with these differential tests.

1. The First Matter to be Determined was the Nature of the Cultural Characters iN REGARD TO WHICH STREPTOCOCCI EXHIBIT THE SHARPEST DIFFERENCES INTER SE.

The laboratory procedure by which it was attempted to obtain an answer to this question was as follows : 12 streptococci, representative of the group as found not merely in

I A useful summary of the evidence for and against the unity of streptococci is contained in an article by Besredka in the Bulletin de l'Institut Pasteur, vol. ii., 1904, Nos. 16 and 17 man but in nature, were selected for comparison. The sources from which these streptococci had been obtained were saliva, fæces, pus, blood of a case of septicæmia, milk, oyster, dust, and air. Ten of these trial streptococci rendered broth uniformly turbid and therefore belonged to the morphological class of streptococcus brevis. All 12 of the streptococci retained Gram's stain and all save one failed to liquefy gelatin.

Litmus milk was the first medium in which the 12 streptococci were tested. Secondly, they were compared in regard to their ability to produce a change of colour in broth tinted with various dyes, and especially in regard to their ability to produce green fluorescence in neutral red broth, a test I had previously shown to be applicable for the purpose of distinguishing streptococcus brevis, the most abundant and constant micro-organism in normal human saliva, from streptococcus pyogenes. $^{2}$ Thirdly, the 12 streptococci were compared in regard to their ability to decompose with an acid reaction some 30 different chemical compounds belonging to the carbohydrate, glucoside, and polyatomic alcohol series respectively.

As a result of this investigation a number of tests were found available for differentiating streptococci and of these differential tests the following nine were selected for routine employment. ${ }^{3}$ 1. The question as to the clotting of litmus milk in three days at $37^{\circ} \mathrm{C}$. 2. The reduction of neutral red broth during incubation anaerobically for two days at $37^{\circ} \mathrm{C}$. 3. The production of an acid reaction in three days aerobically at $37^{\circ} \mathrm{C}$. when cultivated in slightly alkaline broth containing 1 per cent. of saccharose. 4. Ditto, but lactose. 5. Ditto, but raffinose. 6. Ditto, but inulin. 7. Ditto, but salicin. 8. Ditto, but coniferin. 9. Ditto, but mannite.

Extra tests.-Streptococci that decompose mannite with an acid reaction may with advantage be also tested in the same way against sorbit, glycerine, and isodulcit or rhamnose.

The broth used in these decomposition tests was ordinary beef broth freed from sugar by cultivating bacillus col therein for three days at $37^{\circ} \mathrm{C}$. and then sterilised, filtered, rendered slightly alkaline, and tinted with litmus. Dr. A. C. Houston, however, has recently devised a more convenient and cheaper medium which I now use. This medium consists of distilled water containing lemco, 1 per cent. ; peptone, 1 per cent.; sodium bicarbonate, $0 \cdot 1$ per cent.; and ten cubic centimetres per cent. of a 10 per cent. watery solution of ordinary solid litmus. Control tests made by growing streptococci in these media alone invariably gave negative results $q u \hat{a}$ change of colour of the litmus in the direction of acid. In the differential tests the proportion in which the carbohydrate, glucoside, or polyatomic alcohol was added was 1 per cent

I have not so far attempted to investigate the chemical details of the process by which streptococci manufacture acid from these substances but it is more than probable that the action is one of hydrolysis. The acids formed are probably lactic and acetic and from the suggestive work of Ainley Walker and $\mathrm{Ryffel}{ }^{ \pm}$it is possible that formic acid is also produced. The discovery of Walker and Ryffel ${ }^{5}$ that traces of formic acid are actually obtainable from the bodies of stroptococci themselves is one of much clinical interest.

Having obtained in the fashion described therefore a series of definite tests for differentiating streptococci by their biochemical properties, the next step was to apply the tests to a large number of these micro-organisms. Up to the present between 800 and 900 streptococci have been examined with results that will now be briefly considered.

\section{STREPTOCOCCI From THE HumaN Body iN HEALTH.}

(a) Saliva.-In course of a quantitative bacteriological analysis of samples of saliva from various normal personsan investigation made previously to the acquirement of the differential tests-I had found that streptococci were by far the most abundant micro-organisms in normal saliva and I showed that by the culture test in broth and streptococcus brevis as index the presence of so minute a particle as $0.000,000,1$ cubic centimetre of human saliva could be detected. Later I examined a series of infants' mouths soon after birth and showed that, although streptococcus brevis is absent at birth, the oral cavity becomes infected with this micro-organism within 24 hours of birth. 
Saliva, therefore, is a secretion that affords ample opportunity for the study of streptococci. Accordingly, samples of saliva were obtained from 22 different normal individuals and in each case about a dozen specimens of the streptococci present to over 100,000 per cubic centimetre of the saliva were isolated and tested. Altogether 300 streptococci of normal saliva were in this way subjected to the nine differential tests. As a result it was found that all these 300 streptococci of normal saliva had two characters in common-they all produced an acid reaction in broth containing saccharose and they all quite failed to produce such change in broth containing mannite. The negative reaction to mannite of all these 300 streptococci of normal saliva is especially important, as will be seen later.

Although the 300 salivary streptococci behaved alike in two of the nine differential tests, they differed so much in the remaining seven tests that they were split up by them into no less than 48 different types. The vast majority of these types, however, were rare. Thus :-

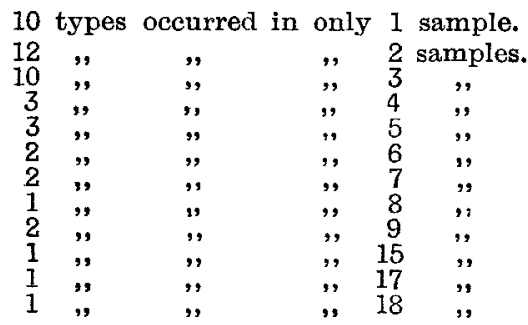

The characters of the five streptococci most abundant in normal human saliva (22 samples) are seen in Table I.

TABLE I.

\begin{tabular}{|c|c|c|c|c|c|c|c|c|c|c|c|}
\hline requency. & $\frac{\dot{0}}{0}$ & 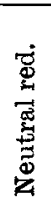 & 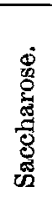 & 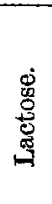 & 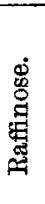 & $\frac{\dot{g}}{\Xi}$ & 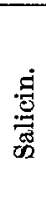 & 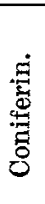 & 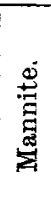 & 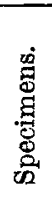 & 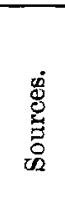 \\
\hline $\begin{array}{l}1\left\{\begin{array}{l}a \\
3 \\
b\end{array}\right. \\
4\left\{\begin{array}{l}a \\
b\end{array}\right.\end{array}$ & $\begin{array}{l}+ \\
+ \\
+ \\
- \\
+\end{array}$ & $\begin{array}{l}+ \\
+ \\
- \\
- \\
+\end{array}$ & $\begin{array}{l}+ \\
+ \\
+ \\
+ \\
+\end{array}$ & $\begin{array}{l}+ \\
+ \\
+ \\
+ \\
+\end{array}$ & $\begin{array}{l}+ \\
- \\
- \\
-\end{array}$ & $\begin{array}{l}- \\
- \\
- \\
- \\
-\end{array}$ & $\begin{array}{l}- \\
- \\
- \\
- \\
+\end{array}$ & $\begin{array}{l}- \\
- \\
- \\
-\end{array}$ & $\begin{array}{l}- \\
- \\
- \\
- \\
-\end{array}$ & $\begin{array}{l}43 \\
41 \\
24 \\
16 \\
15\end{array}$ & $\begin{array}{l}17 \\
18 \\
15\end{array}$ \\
\hline
\end{tabular}

I believe that the first two of the above streptococci, and possibly the third and fourth -also, are practically always present in normal human saliva. As regards virulence, it may be said that a large number of streptococci isolated from normal human saliva were tested upon mice but the result was uniformly found to be negative.

(b) Faces.- -Some years ago Dr. Houston pointed out that streptococci, by reason of their constancy and relative abundance in sewage, form a means whereby sewage pollution can be detected. Recently, with special view to determining the question whether any particular type or types of streptococci were more valuable than others as an index of fæcal pollution, he isolated a total of 300 streptococci from 20 normal stools and submitted each of these streptococci to eight of the nine differential tests, the test omitted by him being that in coniferin. Each streptococcus examined was present to at least 100,000 per gramme of fæces; in the majority of the stools streptococci were found to exceed 1,000,000 per gramme and in some they exceeded $10,000,000$ per gramme. The result of this investigation is fully reported by Dr. Houston in the report of the medical officer of the Local Government Board for 1903-04, pp. 487514.

By the eight tests the 300 frcal streptococci were found by Dr. Houston to be differentiated into 40 different types. But as in the case of the salivary streptococci most of the types were comparatively rare. Thus:-

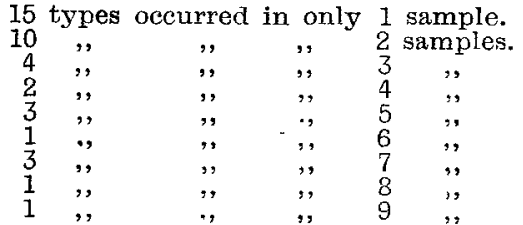

The characters of the five streptococci most abundant in normal human fæces (20 samples) are seen in Table II. which I have compiled from Dr. Houston's results.

TABLE II.

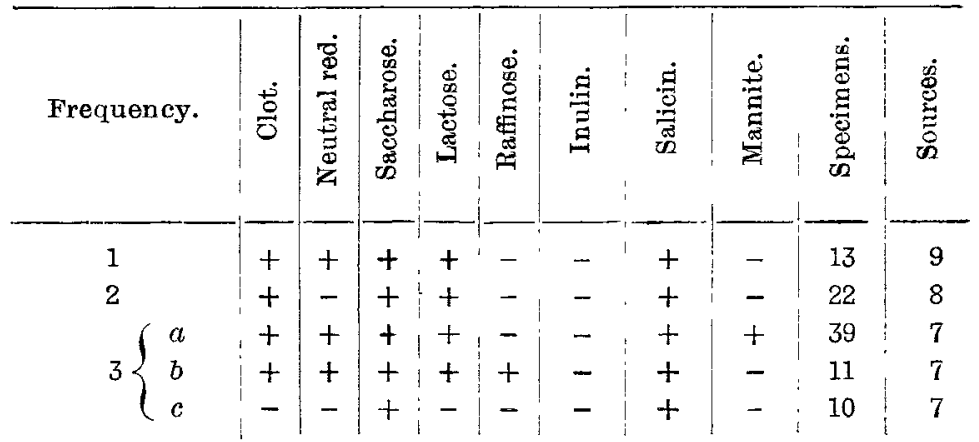

It is noteworthy that all the five streptococci found most frequently in fæces should have given a positive reaction in salicin, and it is to be regretted that the test in coniferin was omitted, for I have found that streptococci that give a positive reaction in salicin can be further subdivided according as they give a positive or negative reaction in coniferin. The streptococcus first in frequency in fæces is seen to be identical in all respects, save as regards salicin, with one of the two streptococi equal first in frequency in saliva. It will be observed also that the streptococcus second in frequency in fæces is identical with the streptococcus third in frequency in saliva in all respects, save as regards salicin. Although the next streptococcus ( $3 a$ ) was only equal third in frequency in fæces as judged from the sample stand point, more actual specimens of it were obtained by Dr. Houston than of any other. The streptococcus in question gave six positive reactions and what is especially noteworthy about it is that it produced a positive reaction in mannite. One of the streptococci $(3 b)$ equal third in frequency in fæces is identical with a streptococcus $(4 b)$ equal fourth in frequency in saliva. The last of the five frcal streptococci (3e) gave a positive reaction in only two of the tests-viz., in saccharose and salicin. Dr. Houston examined the virulence for mice of a large number of streptococci from normal fæces but he always found it to be negative.

3. ApPlication of THESE RESUlts for the PuRPose OF Detecting the Presence of Particles of Saliva OR OF FAECAL MATTER RESPECTIVELY.

Since streptococci are particularly abundant in saliva and fæces of normal persons, and since in each of these two secretions respectively certain distinct types of streptococci occur far more frequently than others, the presence of these particular types of streptococci may be used as a test whereby the presence of particles of material of either kind may be detected.

It is hardly necessary to observe that from the point of view of preventive medicine the importance of being able to identify the presence of particulate material derived from the mouth or intestine is great. For where environment is such that particulate pollution derived from the human mouth or intestine has continual access to the alimentary or respiratory system of others, it is only a matter of time and opportunity for infection to be successfully transmitted by the same route. Tests, therefore, by which particulate material derived from mouth or intestine can be identified, and the frequency and extent of such pollution measured are tests by which the danger of the access of morbific virus may be discerned and the efficiency of measures adopted with a view to preventing such access gauged.

The two chief vehicles by which infection is liable to be transferred are air and food, especially drinking water. In the case of air, the particulate pollution which appears to be most fertile from the point of view of infection is material derived from the mouth ; in the case of water, on the other hand, the form of particulate pollution by which the transfer of disease is most often effected is that emanating from the bowel. The well-known circumstances of a number of epidemics of typhoid fever and cholera are witness to the reality of water-borne disease, and the high infectivity of processes such as influenza and diphtheria illustrates the facility with which zymotic disease affecting the respiratory passages may spread through air. As regards the comparative importance of air and water respectively as vehicles of infection, there can be little doubt that, so far as can at present be seen, far more disease is conveyed by air 
than by water, and this, perhaps, is hardly to be wondered at when it is realised, amongst other things, that a man consumes in a day roughly 5000 times as much air as water.

The chief experience which I have had up to the present in applying these streptococcic tests for the purpose of detecting salivary or fæcal pollution respectively has been in applying them to air. The result of that experience is briefly as follows. As regards salivary pollution I may say that, at one time or another, I have obtained examples of all the five streptococci most characteristic of saliva from the air of inhabited rooms. The streptococcus which I have found to occur most frequently in circumstances when air is subject to particulate pollution derived from the human mouth is the streptococcus first in the list of the streptococci recovered most frequently from saliva. As regards fæcal pollution, I may say that I have obtained the first of Dr. Houston's fæcal streptococci, together with bacillus

TABLE III.

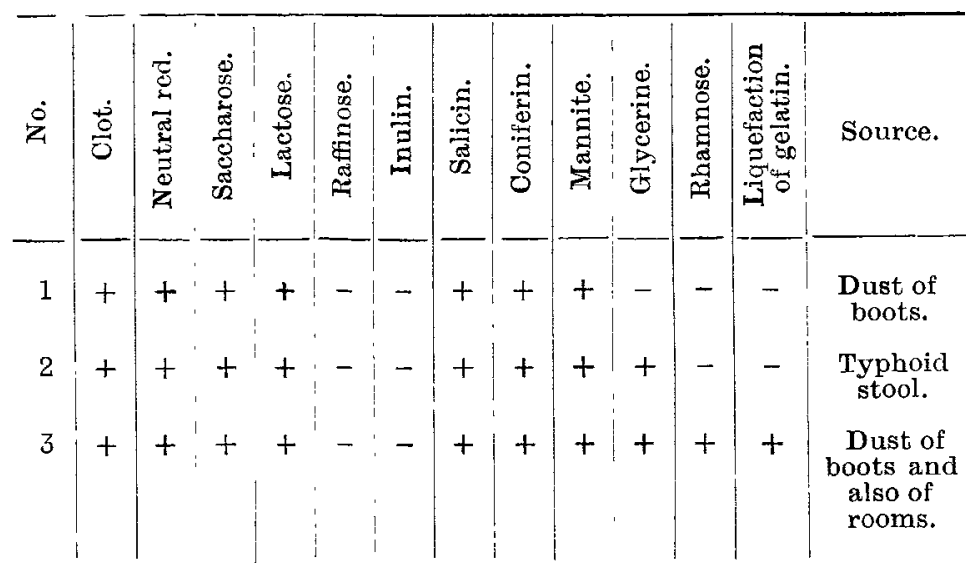

TABLE IV.-Streptococci from Various Septic Processes.

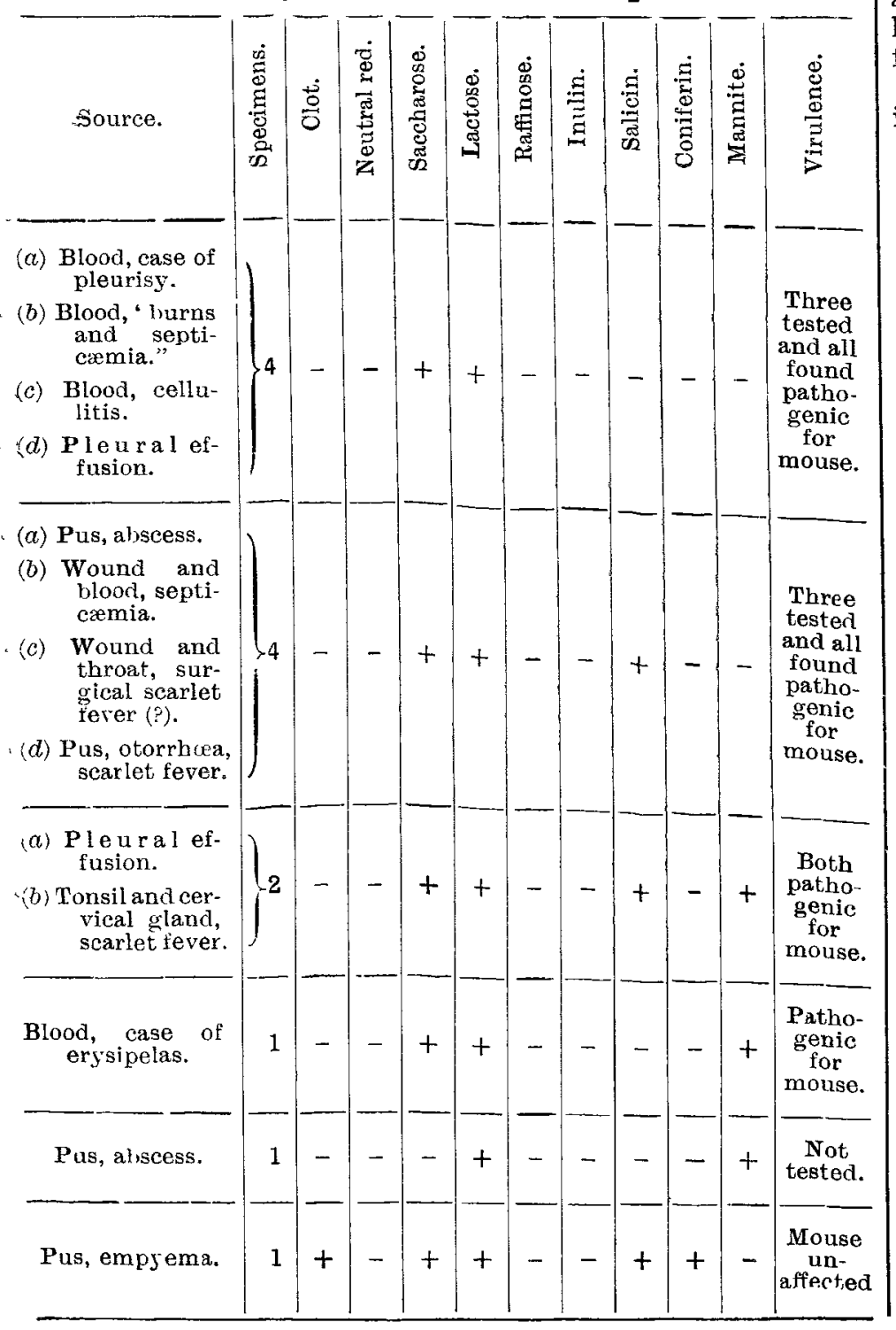

coli, in a broth-plate exposed to air contaminated by particulate material derived from persons' boots. The fæcal pollution, in this instance, was undoubtedly horse manure brought by boots from the streets. I have also obtaincd the third of Dr. Houston's streptococci-viz., $3 a$, producing a positive reaction in mannite, from air polluted by the same agency. The last of Dr. Houston's streptococci-viz., 3c, producing a positive reaction in saccharose and salicin only, is common in street dust and air; it is, in fact, a variety of the streptococcus which, from its frequent occurrence in the air of London, I have termed the "air streptococcus." Other varieties of the streptococcus produce positive reactions in saccharose, salicin, and coniferin; or in the last two alone.

The most active streptococci, in the chemical sense, which I have set found, were isolated from fæcal matter or from dirt brought from the streets by persons' boots. In the latter case the streptococci were probably derived from horse manure. The chief reactions given by three of these streptococci are seen in Table III.

\section{Streptococci from the Human Body in Disease.}

Altogether some 20 streptococci of this category have been examined by $m e$ in the nine tests. For most of these streptococci I am indebted to Dr. F. W. Andrewes or to Dr. T. J. Horder. The characters of the streptococci obtained from various septic processes are seen in Table IV.

It is seen from these results that the streptococcus which has been found up to the present to be most frequently engaged in septic cases either gives positive reactions to saccharose and lactose only or gives these two reactions with the addition of a positive reaction in salicin. The former type of streptococcus, but in a nonvirulent stage as regards the mouse, is the fourth most frequent streptococcus in normal human saliva. Another type of pathogenic streptococcus met with gives a positive reaction in mannite. These and the other results recorded in the table indicate that there is considerable diversity amongst streptococci occurring in cases of sepsis. It is highly desirable that the degree of this diversity should be further determined.

Ulcerative endocarditis. - The characters of streptococci isolated from five cases of this disease are seen in Table T.:-

TABLE V.

\begin{tabular}{|c|c|c|c|c|c|c|c|c|c|c|c|}
\hline Source. & 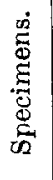 & : & 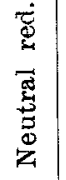 & 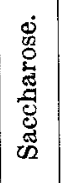 & 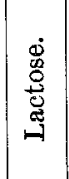 & 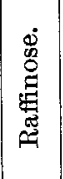 & 节 & 离 & 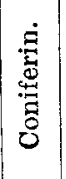 & 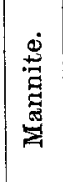 & 总 \\
\hline $\begin{array}{l}\text { Recovered from } \\
\text { the blood of a } \\
\text { patient during } \\
\text { life by Dr. } \\
\text { Horder. }\end{array}$ & 1 & + & + & + & + & + & - & - & - & - & $\begin{array}{c}\text { Mouse } \\
\text { died in } \\
\quad 48 \\
\text { hours. }\end{array}$ \\
\hline $\begin{array}{c}\text { Ditto; another } \\
\text { case. }\end{array}$ & 1 & + & + & + & + & - & - & - & - & - & $\begin{array}{c}\text { Not } \\
\text { tested. }\end{array}$ \\
\hline $\begin{array}{l}\text { Recovered from } \\
\text { the heart valve } \\
\text { post mortem in } \\
\text { two cases by } \\
\text { Dr. Andrewes. }\end{array}$ & 2 & + & + & + & + & + & - & + & + & - & $\begin{array}{c}\text { Mouse } \\
\text { un- } \\
\text { affected }\end{array}$ \\
\hline $\begin{array}{l}\text { Ditto; another } \\
\text { case. }\end{array}$ & 1 & + & - & + & + & + & - & + & + & - & $\begin{array}{c}\text { Mouse } \\
\text { un- } \\
\text { affected }\end{array}$ \\
\hline
\end{tabular}

From their behaviour to the differential tests it is seen that these s'reptococci of ulcerative endocarditis are different from the pathogenic streptococci previously examined. In view of the well-known theory of Hunter and others respec:ing the etiology of this affection, it is a matter of considerable interest to observe that the first two of these streptococci of malignant endocarditis are identified by the tests with streptococci found to occur more frequently and extensively than any other micro-organism in normal human saliva.

5. Pathogenic Streptococci Recovered from SoUrces OUTSIDE THE HUMAN BODY.

Two streptococci of this category have been met with and submitted to the tests. Their characters are seen in Table VI. 
TABLE VI.

\begin{tabular}{|c|c|c|c|c|c|c|c|c|c|c|}
\hline Source. & $\frac{+}{0}$ & 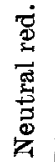 & 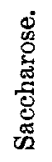 & 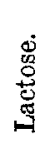 & 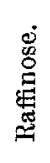 & $\stackrel{\stackrel{\Xi}{\Xi}}{\Xi}$ & $\frac{\dot{E}}{\mathscr{E}}$ & 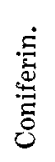 & 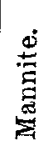 & Virulence. \\
\hline $\begin{array}{l}\text { 1. Recorered in } \\
\text { pure culture } \\
\text { from the heart's } \\
\text { blood of a mouse } \\
\text { fed on milk sus- } \\
\text { pected of causing } \\
\text { throat illness at } \\
\text { Woking. }\end{array}$ & - & - & + & + & - & - & + & - & - & $\begin{array}{c}\text { Mouse } \\
\text { died in } \\
48 \text { hours. }\end{array}$ \\
\hline $\begin{array}{l}\text { 2. Recovered in } \\
\text { pure culture } \\
\text { from the heart's } \\
\text { blond of a mouse } \\
\text { dead three days } \\
\text { after injection } \\
\text { with the dust of } \\
\text { an inhabited } \\
\text { room. }\end{array}$ & + & - & + & + & $:$ & - & + & - & - & $\begin{array}{c}\text { Mouse } \\
\text { died in } \\
48 \text { hours. }\end{array}$ \\
\hline
\end{tabular}

The first of these two streptococci was isolated from a sample of purulent milk that had been associated with the production of an epidemic of "throat illness" amongst consumers. Dr. R. W. C. Pierce of Guildford kindly provided me with this material. The reactions of the streptococcus are seen to be identical with those of one of the commonest streptococci of sepsis. The second virulent streptococcus was obtained from dust on the floor of an inhabited room. In its response to the differential tests this streptocoscus is identical with a streptococcus second in frequency in normal fæces. Dr. Houston, however, it will be remembered, did not succeed in getting a virulent specimen of this or of any other streptococcus from that source.

6. The Stability of these Reactions of Streptococci.

On several occasions I have re examined a streptococcus in the differential tests after it had been in culture for periods up to a fortnight, and up to the present time I have always found that such streptococci respond to the tests in exactly the same manner as when first isolated. In order to put the matter of the stability of reactions to a more severe test 1 passed 11 streptococci through mice and examined their reactions again on recovery from the animal tissues. Full particulars of these experiments are seen in the report of the medical officer for 1903-04, pp. 417-19. Nine of the 11 streptococci were found to respond to the tests in exactly the same manner as prior to passage through the mouse. Two other streptococci, however, became modified; one streptococcus which previously had given a positive response to saccharose and lactose only was found on recovery from the mouse to give an additional positive reaction in salicin; the other streptococcus lost its power, which was but feeble in the first instance, of producing green fluorescence in neutral red broth. The only two of the nine reactions therefore that there is at present the slightest reason for doubting the stability of are those in salicin and neutral red.

Provisional Conclusions.

The differential tests which I have recommended in previous reports and applied during recent years to the careful study of the "strepto-biology" of milk, saliva, water, excremental matters, and morbid and other materials afford, in my opinion, a definite basis (hitherto lacking) upon which to classify streptococci. I am not without lope that the foregoing tests for differentiating streptococci may also serve a useful purpose in connexion with serum therapeutics. At present the choice of an antistreptococcic serum to combat a particular case of streptococcus infection is apt to be speculative in character. This speculative attitude is founded largely on the erroneous impression that streptococci still remain incapable of differentiation. Briefly, the doctrine of the unity of streptococci has arisen chiefly from inability by use of the older laboratory tests to discriminate between specimens of streptococci which in point of fact differed conspicuously in origin and perchance also in morphology and in their behaviour subsequently in animal inoculation experiments. So it came to pass that the view gradually gained currency that because one or another time-worn laboratory test failed to distinguish streptococci believed on sound grounds (clinical or other) to be totally different in character, the belief of dissimilarity must needs be abandoned. The chief object of my paper is to show that the individuality of streptococci is real, not apparent; and that by the use of the tests I have suggested their preliminary classification is already possible and practıcable.

\section{Clinical 繁otes: \\ MEDICAL, SURGICAL, OBSTETRICAL, AND THERAPEUTICAL.}

\section{A CASE OF CONGENITAL UMBILICAL HERNIA CONTAINING MECKEL'S DIVERTICULUM.}

BY A. J. LANDmaN, M.B., CH.B. VICT.,

HOUSE SURGEON TO THE MANCHESTER TICTORLA MEMORIAL JEWISH HOSPITAT.

THE following case seems to be worthy of record on account of the great rarity of the condition.

A female infant, aged one day, was brought to the Manchester Victoria Memorial Jewish Hospital with a swelling at the umbilicus which had been present at birth. The swelling was of about the size of a Tangerine orange and the cover ings consisted of the constituents of the umbilical cord spread over it. The cord had been cut and tied beyond the swelling. The umbilical opening was widened out, being about an inch in diameter. On palpation gurgling could be heard within the sac but the contents could not be reduced into the abdomen. Congenital umbilical hernia or exom. phalos was diagnosed and laparotomy was performed by $\mathrm{Dr}$. Samuel English, honorary medical officer to the hospital, soon after admission. Chloroform was given, a circular incision was made round the sac, and the sac wall wa: separated all round from the underlying intestine, to which it was very adherent. The contents of the sac were small intestine, one part of which consisted of a blind diverticulum and this was the part adherent to the sac wall. Into this diverticulum one of the umbilical vessels entered and there was free hæmorrhage on separating the adhesions. The vessel was ligatured. The contents of the sac were replaced into the abdominal cavity and the sac wall was removed. The wound was then closed by a row of catgut sutures for the peritoneum and silkworm.gut for the abdominal wall. The child recovered well from the shock but on the second day her temperature rose to $104^{\circ} \mathrm{F}$. and reached $105^{\circ}$ on the third day. She vomited bile-stained material and the abdomen was distended and rigid. Death oscurred on the third day.

On post-mortem examination the peritoneum was found to contain some sero-purulent fluid and there were signs of a localised peritonitis which had commenced in the neighbour. hood of the diverticulum. On examining the intestine the diverticulum was found to be situated about two and a half feet from the ileo-cæcal junction. It was about two inches long: and double the width of the small intestine. The specimen was removed and preserved. The spleen was enlarged and the bladder was distended but all the other organs were normal.

The condition found in this case is an interesting anomaly of development. Intra-uterine adhesions had occurred between Meckel's diverticulum (which represents the remains of the vitello-intestinal duct of the embryo) and the coverings of the umbilical cord and prevented its retraction into the abdomen. I am indebted to Dr. English for permission to publish this case.

Manchester.

\section{A CASE OF NASAL OBSTRUCTION FROM AN UNUSUAL CAUSE.}

By James Walker Downie, M.B. GlasG,

LECTURER ON DISEASES OF THE NOSE AND THROAT AT THE UNIVERITY OF GLASGOW.

A MAN who was recently referred to me on account of an extensive intranasal ulcerative lesion associated with con. siderable deformity of the nose also complained of nasal blockage. The cause of the latter proved to be so unusual that I venture to have it noted in THE LANCET as a matter 